monografico: antropología del turismo, texto 8: 101-108.

\title{
EL DEBATE SOBRE LA AUTENTICIDAD EN LA ANTROPOLOGÍA DEL TURISMO
}

\author{
Norma FULLER \\ Pontificia Universidad Católica del Perú \\ nfuller@pucp.pe
}

\section{THE DISCUSSION ON THE AUTHENTICITY IN ANTHROPOLOGY OF TOURISM}

Resumen: Existe un debate intenso dentro de la antropología del turismo sobre las consecuencias de que las expresiones culturales se conviertan en artículos de consumo. En un primer momento los antropólogos denunciaron los efectos negativos de su comercialización y espectacularización. Sin embargo, en la actualidad muchos de ellos han tomado distancia frente a estas posiciones argumentando que no es posible determinar cuáles expresiones culturales son auténticas ni quién está autorizado para decidirlo. Dentro de esta línea propongo que la autenticidad no sería una cualidad inherente a un rasgo o fenómeno cultural. Sería un proceso social, una lucha en la cual intereses en conflicto tratan de imponer su versión de la historia y apropiarse del derecho de representarla. Para ilustrarlo analizo tres casos de disputas por la autenticidad que surgieron en el Perú: Los Raymis. La fiesta del Carmen en Paucartambo, Cusco, y el ritual de la Ayahuasca.

Abstract: Presently, there is an intense debate within Anthropology of Tourism regarding the consequences of cultural expressions becoming consumption goods. Initially, anthropologists denounced the negative effects of their commodification and spectacularization. However, currently many experts in the field have distanced from such views, arguing that it isn't possible to precise which cultural expressions are authentic and who have the authority to decide the issue. Following the latter line of thought, this work advances the idea that authenticity would not be an inherent feature of cultural traits or expressions. It would rather be a social process, and a struggle in which conflicting interests seek to impose their own version of history and appropriate the right to represent it. To illustrate such view this article will analyze three cases of disputes surrounding authenticity that emerged in Peru: The Raimis; the Virgen del Carmen festival in Paucartambo, Cusco; and the ritual of Ayahuasca.

Palabras clave: Antropología del turismo; Comercialización de la cultura; Autenticidad cultural; Autoridad cultural; Perú

Anthropology of Tourism; Commodification of culture; Cultural authenticity; Cultural authority; Peru 


\section{Introducción ${ }^{1}$}

La actividad turística ha sido un campo de interés para la antropología desde la década de los 60. Desde ese entonces, la literatura sobre el tema ha proliferado y se ha desarrollado un corpus teórico importante. Al respecto existe un debate intenso alrededor de las consecuencias que puede tener para las poblaciones receptoras el hecho de que sus expresiones culturales se conviertan en artículos de consumo. En un primer momento los teóricos del turismo (Boorstin 1992 [1961]), Greenwood ( [1978] 1989) pusieron el acento en el hecho de que la demanda turística genera transformaciones en las culturas locales de modo tal que las fiestas tradicionales se convierten en espectáculos y las artes en producciones en masa adaptadas a los gustos de los turistas. En ese sentido estaríamos asistiendo a un proceso de comercialización de la cultura, que se adorna, clasifica y vende por un precio variable (Urry 1996). Así, aspectos de las culturas receptoras que forman parte de sus tradiciones, estilos de sociabilidad, expresiones artísticas, rituales, etc., son transformadas para convertirlos en bienes de consumo masivo. Estos cambios se observan en la venta de cosas antes impensables como la entrada a una iglesia. En su forma más extrema el turismo reduce a las poblaciones y su cultura, a objetos de consumo que se ven reducidos a productos "exóticos." En suma, la industria turística habría cuadriculado la tierra convirtiéndola en «recorridos» y hecho de la naturaleza y de la cultura un «producto», una ficción que copia paisajes, expresiones culturales al extremo de convertirlas en versiones "mejoradas" "hiper reales" de los originales (Augé 1998)

Desde entonces existe un animado debate sobre la problemática de la autenticidad en el turismo. Para los escépticos, la experiencia turística es homogeneizada y artificial. Los turistas no se interesan en conocer la cultura local -que por lo general les resulta impenetrable- y se contentan con los "pseudo acontecimientos" preparados para ellos por los agentes turísticos. En el lado opuesto, teóricos como MacCannell (1999 [1976]) refutan este argumento y remarcan que, por el contrario, los turistas demandan autenticidad y esta es una de las principales motivaciones del viaje. Señalan que la retórica del turismo está llena de expresiones sobre la autenticidad de lo observado: "esa es una típica casa nativa", "este es el lugar donde el héroe cayó", "este es el manuscrito original del acta de independencia".

De acuerdo con MacCannell ([1976] 1999) toda sociedad necesita dramatizar sus mitos centrales y su estructura social. De allí la existencia de rituales que representan a la nación (como los desfiles militares), de monumentos que relatan los momentos clave de su historia y de héroes que sintetizan sus ideales. Desde este punto de vista los tours y los sight seeings no son una mera colección al azar de monumentos o lugares, ellos narran historias sobre la identidad de la sociedad observada, expresan su sistema de valores y nos devuelven una imagen de la sociedad como un todo integrado. Así por ejemplo un itinerario en USA contendrá establecimientos domésticos, comerciales e industriales, ocupaciones, servicios públicos, transportes vecindarios y comunidades Todas estas escenificaciones representan el modo en que la sociedad Americana se ve a sí misma. Para MacCannell, esta sensación de pertenencia se habría perdido debido a la fragmentación de la vida moderna generando en las personas la necesidad de recuperarla. Una de las maneras de lograrlo es a través de la experiencia de acercarse a otra cultura $u$ otra historia. Los productos turísticos responden a esta necesidad.

Sin embargo, MacCannell sigue pensando que el turismo es un productor de escenografías. Para explicarlo usa los conceptos de palco (front region) y bastidores (back region) para desarrollar su teoría del escenario (stage setting). Según señala, existen diver-

1 Ponencia presentada en el V Congreso de la Asociación Portuguesa de Antropología APA. Vila Real, 8- 11 Setiembre 2013. 
sas estrategias para montar estas escenificaciones: "la representación", "la mistificación" y la "pequeña mentira". Todas ellas suponen la existencia de un escenario, aquello que se muestra a los turistas y de unas bambalinas desde las que se dirige el espectáculo. Un caso típico son los resorts o playas del Caribe del Pacífico sur donde todas las actividades están producidas y planificadas para proporcionar relax y dar al turista la impresión de visitar un mundo paradisíaco. Entretanto, quienes producen estas bellas imágenes trabajan arduamente para mantener las playas limpias, preparar banquetes exóticos y crear un ambiente de alegría y distensión.

Actualmente, ya son muchos los antropólogos (Cohen 1996, Urry 1996a, 1996b, 2002, Santana 2003, Bruner 2005, Fuller 2009) que han tomado distancia frente a estas posiciones debido a que tienden a esencializar a las culturas al suponer que existe una versión real o auténtica que el turismo dañaría. Más aun, en un mundo globalizado no se puede hablar de culturas aisladas y diferentes mundos o autenticidades en peligro. Los turistas de hoy saben que el turismo es una industria organizada y que los que se les ofrece ha sido preparado para su consumo. Saben también que la autenticidad es fabricada y lo que les interesa es que la representación sea de calidad. Desde este punto de vista, lo que se escenifica en el turismo no es una mera copia sino una nueva realidad específicamente construida para una audiencia determinada.

Por otro lado, es importante tener en cuenta que el turismo no es el único factor que interviene en este fenómeno. Las formas de expresión cultural están en continua transformación, precisamente porque son parte de la vida de los pueblos y, en esa medida, se adaptan a los cambios en curso, a los estilos cambiantes, y dialogan con las influencias de un mundo crecientemente globalizado. El patrimonio no es un objeto fijo y estable sino una construcción social que se modifica se compone y se recompone con el tiempo. Además, podríamos preguntarnos ¿qué no es representado en una cultura? ¿En qué consiste la autenticidad cultural? Si toda cultura es, en cierto sentido, autenticidad representada y está en cambio permanente, ¿por qué la representación turística debería ser vista como destructiva y por qué los cambios que impulsa serían tan negativos?

El turismo puede ser entendido como una puesta en escena en la cual se produce una nueva forma de expresión cultural específicamente construida para una determinada audiencia. Ello porque los agentes, los productores turísticos y las poblaciones locales buscan activamente interpretar los deseos de los turistas y tienden a reelaborar sus manifestaciones culturales especialmente para esta audiencia. Se trataría pues de fenómenos culturales nuevos porque han sido creados específicamente para ese fin. De este modo, muchas danzas se acortan para corresponder al horario del tour, se editan para volverlas comprensibles a la audiencia turística y se escenifican periódicamente en lugares predeterminados y en ciertos horarios.

Sin embargo, en la medida en que el turismo vende cultura, precisa convencer a los visitantes de la autenticidad de lo que ofrece. Por ello este tema se ha ido convirtiendo en un eje del debate sobre el valor de lo que se ofrece que ha propiciado el surgimiento de políticas de conservación del patrimonio, de expertos autorizados para validarlos y de debates entre los diversos autores en torno a quien detenta la autoridad para determinar cuál es la versión autentica de esta o aquella costumbre.

Dentro de esta línea, propongo que es el momento de cambiar el giro del debate para superar la tendencia a movernos dentro de la dualidad auténtico/ inauténtico, verdadero/ falso, realidad/ espectáculo que impregna las teorías sobre la relación entre turismo y cultura. En la práctica la disputa sobre la autenticidad se ha convertido en un juego de poder, entre diversos actores sobre quién tiene la autoridad para decidir qué es auténtico. Por tanto, la autenticidad no sería una cualidad inherente a un rasgo o fenómeno cultural. Sería un proceso social, una lucha en la cual intereses en conflicto tratan de imponer su versión de la historia y apropiarse del derecho de representarla. 
En este trabajo analizaré tres casos de disputas por la autenticidad que surgieron en el Perú: La fiesta del Carmen en Paucartambo, Cusco, Los Raymis y el ritual de la Ayahuasca, para ilustrar las complejas relaciones que envuelve el uso del patrimonio cultural como recurso turístico. Mi objetivo es mostrar en qué medida la antropología puede contribuir a comprender estos fenómenos y debería ser tenida en cuenta cuando se diseñan políticas públicas al respecto

\section{El inti raymi}

Uno de los casos paradigmáticos de la espectacularización de la cultura es el de los festivales y los espectáculos públicos. Se supone que estos expresan la quintaesencia de una cultura porque en ellos se expresan sus valores centrales y aparecen los personajes representativos de su sociedad. Además, tienen la ventaja de ofrecer, de forma concentrada, en un tiempo y espacio determinados, lo que, de otra manera ocurre de manera dispersa dentro de la fluidez de la vida diaria. De este modo, el festival permite cumplir con las expectativas típicas de cierto turismo: la promesa de acceder a los aspectos inaccesibles de otras culturas. Pero, conocer una sociedad a través de una fiesta que, a su vez, ha sido filtrada por los lentes del espectáculo turístico genera otros problemas: la ilusión de la transparencia frente a la indescifrable complejidad de una cultura, y la imagen de una sociedad como si siempre estuviera de fiesta. Más aún, disfrutar con los otros se convierte en el paradigma del encuentro intercultural y la imagen que se tiene de esa cultura es la de gente que vive en una fiesta perpetua. Finalmente, reduce los encuentros entre personas de diferentes culturas a meras actuaciones de papeles teatrales (Kirshenblatt 1998). En suma, cuando se transforman en atractivos turísticos, los festivales y rituales cambian su sentido y función para adaptarse a las exigencias de visitantes que no conocen sus significados y para los cuales se trata sólo de entretenimiento.

Un buen ejemplo de este hecho lo constituye una de las principales atracciones del turismo cultural en el Perú: los festivales raymis, en los que se escenifican rituales supuestamente prehispánicos en ciudades o pueblos en los que habitan poblaciones indígenas. Estos rituales han sido reconstruidos por académicos, artistas, autoridades locales y agencias de turismo tomando como base crónicas o descripciones de la cultura incaica y las tradiciones locales. Por otro lado, los gestores deben tener en cuenta las expectativas de los turistas porque de ellos proceden los recursos económicos que financian la «gestión de la tradición» en el ámbito local.

El primer caso de estos festivales es el Inti raymi del cuzco. Este último se inventó en la década de los cincuenta tomando como fuente las crónicas escritas por españoles o mestizos nacidos luego de la conquista española, que describen los rituales inca. Intelectuales representantes del poderoso movimiento político indigenista propiciaron la reconstrucción de esta fiesta como una manera de celebrar el pasado incaico. Paralelamente, desde la década de los cincuenta del siglo XX, el Cusco ha sido promocionado como la principal atracción turística del Perú debido a su belleza natural y arquitectónica y sobre todo al hecho de haber sido la capital del Imperio Inca. Con el correr del tiempo el inti raymi cusqueño se ha ido convirtiendo en un festival que atrae a multitudes de visitantes.

El éxito de este festival ha llevado a que en la actualidad hayan proliferado los raymis en casi todos los lugares que cuentan con un pasado y restos arqueológicos inca. Con ello han surgido intensas disputas en torno a la autenticidad de los mismos. Por un lado ciudades que fueron importantes sedes inca como Vilcashuaman, reclaman ser las "verdaderas sede del Inti raymi" y han activado una serie de estrategias para sustentar su reclamo. Por otro, lado multitud de municipios rurales han inventado sus propios raymis. Para ello contratan los servicios de historiadores y antropólogos para que los reconstruyan, actores profesionales, generalmente mestizos citadinos para dramatizar los roles del inca, la coya, los sacerdotes, 
etc. El argumento tal como lo resume el alcalde de un municipio cusqueño famoso por sus restos incas es:

\begin{abstract}
"Viendo que el pueblo de Pisac es turístico, es folclórico, y es una cultura netamente propia, desde el Municipio se ha tratado de recuperar toda la actividad tradicional y ponerla al servicio del turismo (...); ¿lo que más puede atraer al turista?: la naturaleza propia de Pisac, sus festividades, que puede ofrecerle la presencia de los hombres andinos que todavía están en la parte alta; y otro, es que el turista pueda apreciar algunas costumbres de la época inca que se reconstruyen de acuerdo a la información de los cronistas" (Washington Camacho, Alcalde Municipal de Pisac, Agosto de 1997. En: Pérez Galán 2006).
\end{abstract}

Si analizamos estos casos encontraremos que se trata de expresiones culturales específicamente construidas "inventadas" (Hobsbawn y Ranger 1984) para una determinada audiencia. Tanto los agentes turísticos como las poblaciones locales buscan interpretar los deseos de los visitantes y elaboran sus manifestaciones culturales especialmente para esta audiencia. Lo que se crea allí es una cultura imaginaria, una fantasía en sí misma, no una cultura vivida cotidianamente sino una performance teatral. Por lo tanto, el turismo sería un teatro improvisado cuyo escenario se ubica en una zona fronteriza en la cual ambos turistas y nativos son actores (Bruner 2003).

Sin embargo, estas disputas en torno a la autenticidad de los raymis también supone determinar quién tiene la autoridad para dar el sello de autenticidad a los festivales (Pérez Galán 2006). Para ello la los agentes turísticos deben negociar con la población, las autoridades regionales y locales y los expertos en la cultura local. Desde este punto de vista el turismo puede ser un nuevo canal de negociación política entre los grupos locales -detentadores de la tradición- y las autoridades municipales y regionales lo que les granjea una cuota de poder y puede, eventualmente, redefinir su posición en la localidad.

\title{
La fiesta del Carmen
}

El caso de la disputa sobre la autenticidad de las danzas de fiesta de la Virgen del Carmen, del pueblo de Paucartambo, en el Cuzco. Ilustra gráficamente las connotaciones políticas de la disputa sobre la autenticidad y como esta no solo moviliza recursos turísticos sino que es una arena donde se definen y redefinen las cuotas de poder de los diferentes sectores sociales y grupos étnicos en una sociedad fuertemente marcada por la tensión étnica como la peruana.

La fiesta de la Virgen del Carmen es uno de los eventos religiosos y festivos más importantes de la región cusqueña. Su rasgo característico es el recorrido de grupos (comparsas) de danzantes ataviados con coloridos trajes que recorren las calles de la aldea siguiendo la procesión. Algunos participantes de las comparsas, entre cuyos miembros existe gente vinculada a la actividad turística así como las empresas cerveceras, promocionan la fiesta como una atracción para visitantes. Como respuesta a la aparición de actores interesados en su uso como consumo turístico, la municipalidad de Paucartambo, ha realizado una serie de actividades dirigidas a controlar el flujo de turistas, así como los productos culturales que se ofrecen. Ahora bien, los argumentos para asumir estas medidas se centran en la autenticidad de las danzas y canciones de la fiesta y sobre su pertenencia como patrimonio a uno u otro grupo. Las autoridades municipales argumentan que las danzas mestizas paucartambinas no representan la verdadera identidad paucartambina porque esta última es indígena. Por lo tanto las verdaderas danzas serían aquellas que pueden certificar su origen indio.

El proceso de apropiación de este recurso cultural es parte de la consolidación del poder de la municipalidad local, que necesita legitimarse frente a las autoridades regionales 
y frente a la población campesina de la provincia, y asegurarse de que los beneficios de la fiesta vayan a la población local. La indigenización del repertorio paucartambino también responde a la necesidad de crear un producto cultural para el mercado turístico que luzca auténticamente "nativo" (Cánepa 2002). De este modo vemos cómo el recurso a la autenticidad puede ser visto como una estrategia de los diferentes grupos para validar sus intereses que, a su vez va construyendo nuevas versiones de la fiesta.

\section{El caso de la ayahuasca}

En las últimas décadas se ha registrado un creciente aumento de turistas que visitan la Amazonía peruana con la finalidad de consumir ayahuasca, una droga con cualidades psicotrópicas que los pueblos nativos usan con fines rituales ${ }^{2}$. Esta última fue dada a conocer al público a través de las obras de William Burroughs y Allen Ginsberg, poetas de la generación beat que reaccionaron contra las presiones de la vida moderna y buscaron formas de vida alternativas a través del consumo de drogas y la exploración en formas no occidentales de religiosidad. Sus escritos atrajeron a viajeros en busca de experiencias que los alejen de la presión del mundo moderno y los inicien en la sabiduría perdida que, supuestamente, reside en estas formas primigenias de conocimiento.

Como consecuencia de este creciente interés en los rituales de la ayahuasca, la iniciación en el consumo de esta droga se ha convertido en uno de los principales atractivos turísticos de la Amazonía peruana. Paralelamente, han surgido diversas agencias que ofrecen esta experiencia y han proliferado los especialistas en estos rituales que se ofrecen a guiar al turista en este viaje iniciático (Patino 2007). Ello ha generado recelo entre los habitantes locales que temen que los extranjeros se apoderen de sus conocimientos. Como respuesta a estas sospechas el Instituto Nacional de Cultura emitió, con fecha 24 de junio de 2008, la Resolución Directoral Nacional N ${ }^{\circ}$ 836, en base a un informe de la Dirección de Registro y Estudio de la Cultura en el Perú Contemporáneo, declarando Patrimonio Cultural de la Nación a los conocimientos y usos tradicionales de la ayahuasca practicados por las comunidades nativas amazónicas. En los considerandos de la resolución se especificaba, entre otras cosas, que:

"los conocimientos y usos tradicionales asociados al Ayahuasca y practicados por las comunidades nativas amazónicas (...) esta especie vegetal (...) cuenta con una extraordinaria historia cultural, en virtud de sus cualidades psicotrópicas (...) dicha planta es conocida por el mundo indígena amazónico como una planta sabia o maestra que enseña a los iniciados los fundamentos mismos del mundo y sus componentes. Los efectos de su consumo constituyen la entrada al mundo espiritual y a sus secretos, es así que en torno al ritual de Ayahuasca se ha estructurado la medicina tradicional amazónica (...) la práctica de sesiones rituales de Ayahuasca constituye uno de los pilares fundamentales de la identidad de los pueblos amazónicos y que su uso ancestral en los rituales tradicionales, garantizando su continuidad cultural, está vinculado a las virtudes terapéuticas de la planta (...) que se busca la protección del uso tradicional y del carácter sagrado del ritual de Ayahuasca, diferenciándolo de los usos occidentales descontextualizados, consumistas y con propósitos comerciales".

Como puede apreciarse, el discurso se articula en torno a la noción de despojo y de conservación de las raíces culturales ante el embate del consumo. Sin embargo, si analizamos la polémica es claro que esta no expresa únicamente el temor de las poblaciones que ven transformarse sus costumbres, sino las luchas entre diferentes grupos con respecto la admi-

2 Este brebaje se prepara en base a dos plantas: el ayahuasca (Banisteriopsis caapi) y la chacruna (Psychotria viridis), de efectos alucinógenos. 
nistración de estos recursos. De este modo, queda claro que es determinada asociación ${ }^{3}$ la que está autorizada para autentificar los rituales en torno a la ayahuasca, que estos conocimientos son patrimonio de los pueblos nativos y que la última autoridad la detenta el Estado en tanto guardián del patrimonio de la nación.

\section{Reflexiones finales}

En suma, el debate sobre la relación entre turismo y cultura ha dejado atrás las posiciones puristas que veían en el consumo de tradiciones locales un atentado contra la integridad cultural de las poblaciones receptoras. El turismo ya no puede ser analizado como un factor externo que influye en las tradiciones y expresiones culturales. Se trata de un fenómeno cultural en sí mismo que no sólo transforma costumbres, rituales y paisajes, sino que produce nuevas expresiones y significados.

En lo que se refiere al debate sobre la autenticidad es importante señalar que el patrimonio cultural no es un producto natural. Decidir cuáles expresiones culturales (costumbres, rituales, artes, mitos, monumentos etc.) son representativos o simbolizan la identidad de un grupo o una nación implica llegar a un consenso entre distintos actores sociales que cuentan con la autoridad para legitimarlas. En consecuencia, constituye un campo de confrontación simbólica inevitable, entre las distintas versiones y propuestas de diversos grupos. Es preciso preguntarse entonces ¿Quién activa las versiones sobre el patrimonio?¿Quién representa o dirige la representación? ¿Quién efectúa la selección?

Finalmente, son las diversas interpretaciones, las heterogéneas estrategias ligadas a los nacionalismos, los intereses político-económicos y el mercado los que determinan las lecturas del patrimonio cultural. La autenticidad no sería una cualidad inherente a un rasgo o fenómeno cultural. Sería un proceso social, una lucha en la cual intereses en conflicto tratan de imponer su versión de la historia y apropiarse del derecho de representarla. En ese sentido analizar al turismo como un fenómeno antropológico puede ser de gran utilidad para comprender las relaciones entre grupos especialmente en países donde la diversidad cultural y los conflictos interétnicos son parte central de la realidad social y política.

\section{Bibliografía}

ASPOSTOLOPOULOS, Yiorgos

1996 "Introduction: Reinventing the Sociology of Tourism". En: Aspostolopoulos, Leivadi y Yannakis, eds. The Sociology of Tourism. Theoretical and empirical investigations. London and New York, Routledge, pp. 1-14.

ASPOSTOLOPOULOS, yiorgos; LEIVADI Stella; YANNAKIS, Andrew eds.

(1996) The Sociology of Tourism. Theoretical and empirical investigations. London and New York, Routledge.

AUGÉ, Marc (1998): El viaje imposible. El turismo y sus imágenes. Barcelona, Gedisa.

BOORSTIN, Daniel (1992) [1961]: The Image: A Guide to Pseudo-events in America. New York, Vintage.

BRUNER, Edward

2005 Culture on Tour: Ethnographies of Travel. Chicago University Press.

CÁNEPA, Gisela

2002 "Poéticas y políticas de identidad: el debate por y la creación de diferencias étnicas y culturales". En: Norma Fuller, ed. Interculturalidad y políticas públicas. Desafíos y posi-

COHEN, E. bilidades. Lima, Red para el Desarrollo de las Ciencias Sociales, pp. 273-300.

1996 "The Sociology of Tourism. Issues and Findings". En: Aspostolopoulos, Leivadi y Yiannakis, eds. The Sociology of Tourism. Theoretical and empirical investigations. London

3 El expediente fue elaborado por el Centro Takiwasi-Tarapoto y presentado por la Gerencia Regional de Desarrollo Económico del Gobierno Regional de San Martín ante la Dirección Regional de Cultura de San Martín. 
and New York, Routledge, pp. 51-71.

COMISIÓN ESPECIAL DE TURISMO

1997 Comisión Especial de Turismo de la Amazonía: antecedentes constitutivos, actas y anexos de las reuniones. Lima, Tratado de Cooperación Amazónica. Secretaría Pro-Tempore, 113 p.

FULLER, Norma

2009 Turismo y cultura. Entre el entusiasmo y el recelo. Fondo Editorial de la Pontificia Universidad Católica del Perú.

GRABURN, Nelson

1989 [1978] “Tourism, the Sacred Journey”. En: Valene Smith, coord. Hosts and Guests, The Anthropology of Tourism. 2a. ed. Pennsylvania, Universidad de Pennsylvania, pp. 21-36.

GREENWOOD, D. J.

1989[1978] "Culture by the pound: an anthropological perspective on tourism as cultural commoditization”. En: Valene Smith, ed. Hosts and guests. The Anthropology of Tourism. 2 a. ed. Penssylvania, Universidad de Pennsylvania, pp. 86-107.

HOBSBAWN, Eric Y RANGER, Terence

1984 The invention of tradition. Cambridge University Press, 1984 Cambridge R.U

KIRSHENBLATT-GIMBLETT, Barbara

1998 Destination Culture:Tourism, Museums and Heritage. Berkeley, University of California Press.

MACCANNELL, DEAN

1973 "Staged authenticity: arrangement of social space in tourist setting". En: American Journal of Sociology, 79: 586-603.

1999 [1976] The Tourist. A new Theory of a leisure class. Berkeley, University of California Press.

PATIÑO RABINES, Paola

2007 "Ayahuasca y tecnologías del yo entre consumidores limeños: mecanismo de autoconfiguración en el contexto de la postmodernidad". Tesis para optar el grado de Licenciatura. Lima, Pontificia Universidad Católica del Perú.

PÉREZ GALÁN, Beatriz

2006 "Turismo y representación de la cultura: identidad cultural y resistencia en comunidades andinas de Cuzco". En: Anthropologica, No 24, 29-50.

SANTANA TALAVERA, Agustín

2003 "Patrimonios culturales y turistas". En: Pasos. Revista de Turismo y Patrimonio Cultural. Vol. 1, No 1, pp. 2-10.

URRY, John

1996a "Tourism, Culture and Social Inequality". En: Aspostolopoulos, Leivadi y Yiannakis, eds. The Sociology of Tourism. Theoretical and empirical investigations. London and New York, Routledge, pp. 115-133.

1996b "The Changing Economics of the Tourist Industry". En Apostolopoulos, Leivadi y Yiannakis eds. The Sociology of Tourism. Theoretical and empirical investigations. London and New York, Routledge, pp. 193-218.

2002 The tourist gaze. London, Sage Publications. 